\title{
SiM
}

\section{Weather Variability and Adaptive Management for Rangeland Restoration}

\author{
By Stuart P. Hardegree, Jeanne M. Schneider, and Corey A. Moffet
}

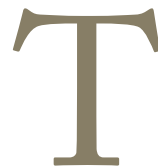

he Ecologically Based Invasive Plant Management (EBIPM) model for restoration planning is based on a conceptual framework for understanding successional dynamics and trajectories, but with specific guidance and tools for practical implementation. ${ }^{1}$ Weather variability impacts all aspects of the successional processes underlying the EBIPM model. ${ }^{2}$ Recent reviews have discussed the interactions of weather and seedbed preparation treatments on site availability and seedbed microclimate. ${ }^{2,3}$ In this paper we will discuss weather variability, and how local weather knowledge can be used in EBIPM planning, interpretation of monitoring data, and development of adaptive management strategies for rangeland restoration.

Weather is the real-time combination of atmospheric inputs that drives seedbed temperature and water relations. Most seedbed preparation and planting treatments are designed to optimize soil microclimate for plant establishment, but these treatments are generally prescriptive and cannot compensate for episodic drought and temperature stress that can occur at a given site and year. ${ }^{3}$ Restoration planners have primarily used weather information for retrospective assessment of success and failure. A recent survey of the rangeland seeding literature observed that for studies reporting some level of successful establishment, the vast majority were conducted in years or establishment seasons with average or above average precipitation. ${ }^{3}$ This implies that weather thresholds may exist below which any given restoration treatment may be unsuccessful.

Climate is the long-term average characterization of weather. Climate data have been shown to be correlated with the historical distribution of plant species and are primarily used to select appropriate plant materials for a given site. ${ }^{3}$ Seeding guides commonly contain tables listing species suitability as a function of average precipitation and soil texture. Unfortunately, the microclimatic requirements for seedling establishment are much more restrictive than the climatological averages that explain the historical distribution of mature plant communities. ${ }^{3}$
Current successional models acknowledge that there is a restricted set of weather conditions under which successful recruitment and establishment can occur. Weather and climate data are increasingly available for remote rangeland locations, but few tools exist to exploit these data in planning and management. ${ }^{2}$ It might be possible in the near future to use real-time weather forecasting to assist in restoration management decisions, which in the Intermountain western United States are often made in the fall, several months before the critical season for plant establishment. ${ }^{2,3}$ Even with forecasting tools, however, weather constraints will require adaptive management for planning and implementation of restoration projects in highly variable rangeland systems. The EBIPM framework uses an adaptive management approach to understand and adjust to uncertainty in the planning process. ${ }^{1}$ The purpose of this article is to outline how weather and climate information can be used to facilitate EBIPM and adaptive-management planning. We have structured the following discussion to follow the eight steps to adaptive management outlined in EBIPM management planning guides. ${ }^{4,5}$

\section{Goal Setting}

Realistic rangeland restoration goals need to take into account the high variability in rangeland weather. Rangelands are generally arid or semiarid, but are also highly variable from year to year. Annual climate indices might be insufficient to characterize expected variability in seedbed microclimate. For example, the correlation between annual and spring precipitation is only $32 \%$ for records in Boise, Idaho, and precipitation alone accounts for only $54 \%$ of the variability in predictions of microclimatic favorability for seed germination. ${ }^{6}$ Boise weather records also show that the inherent variability in precipitation is approximately $25 \%, 40 \%$, and $80 \%$ of the mean for annual, March-May, and monthly precipitation, respectively. ${ }^{6}$ Increased variability in shorter time scales can have a relatively large impact on the periodicity of mortality events that cannot be predicted by analysis of long-term climate averages. ${ }^{6,7}$ Inherent variability in rangeland weather 
may require the adoption of relatively long-term objectives and multi-year management treatments in order to achieve acceptable levels of plant community change.

\section{Information Collection}

Weather information in the western United States is collected and distributed by a large number of agencies and organizations. Fortunately, most of these providers now have webbased data access. The National Oceanic and Atmospheric Administration (NOAA) operates an extensive network of high-quality weather stations that collect hourly data, but these stations are relatively sparse in the western United States and are often located near population centers or along transportation corridors. NOAA also administers a Cooperative Observer Program (COOP) that collects daily precipitation and minimum-maximum temperature information. These lower-resolution data, which are collected manually by volunteers, are available for many more locations than can be found in any other data network. All NOAA weather and climate data are available through the National Climatic Data Center (NCDC). ${ }^{i}$ There are a number of regional, application-specific, weather networks in many states, such as the Pacific Northwest Cooperative Agricultural Weather Network (AgriMet) operated by the Bureau of Reclamation, and the Washington State Agricultural Weather Network (AgWeatherNet). iii The Bureau of Land Management (BLM) deploys a large number of Remote Automatic Weather Stations (RAWS) ${ }^{\text {iv }}$ throughout the western United States, primarily to monitor fire danger. RAWS stations are generally deployed in relatively remote locations in comparison to other weather networks. The Natural Resources Conservation Service (NRCS) also operates the Snow Telemetry $(\mathrm{SNOTEL})^{\mathrm{v}}$ and Soil Climate Analysis Networks (SCAN). ${ }^{\mathrm{vi}}$ Several organizations provide consolidation of weather information sources and climatological products that can also be useful in planning such as the NRCS National Water and Climate Center (NWCC) $)^{\text {vii }}$ and the Western Regional Climate Center (WRCC). viii A global database for historical weather information is also available from the NCDC Web site through links to the World Meteorological Organization (WMO), ${ }^{\text {ix }}$ which maintains a list of meteorological data sources by country.

For more information on the NCDC, see http://www.ncdc.noaa.gov/oa/ ncdc.html.

ii For more information on AgriMet, see http://www.usbr.gov/pn/agrimet/.

iii For more information on AgWeatherNet, see http://weather.wsu.edu.

iv For more information on RAWS, see http://raws.fam.nwcg.gov.

${ }^{v}$ For more information on SNOTEL, see http://www.wcc.nrcs.usda.gov/ snow/.

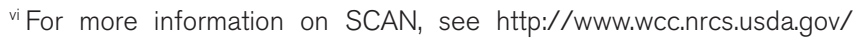
scan/.

vii For more information on NWCC, see http://www.wcc.nrcs.usda.gov.

viii For more information on WRCC, see http://www.wrcc.dri.edu.

ix For more information on WMO, see www.wmo.int/pages/members/ members_en.html.

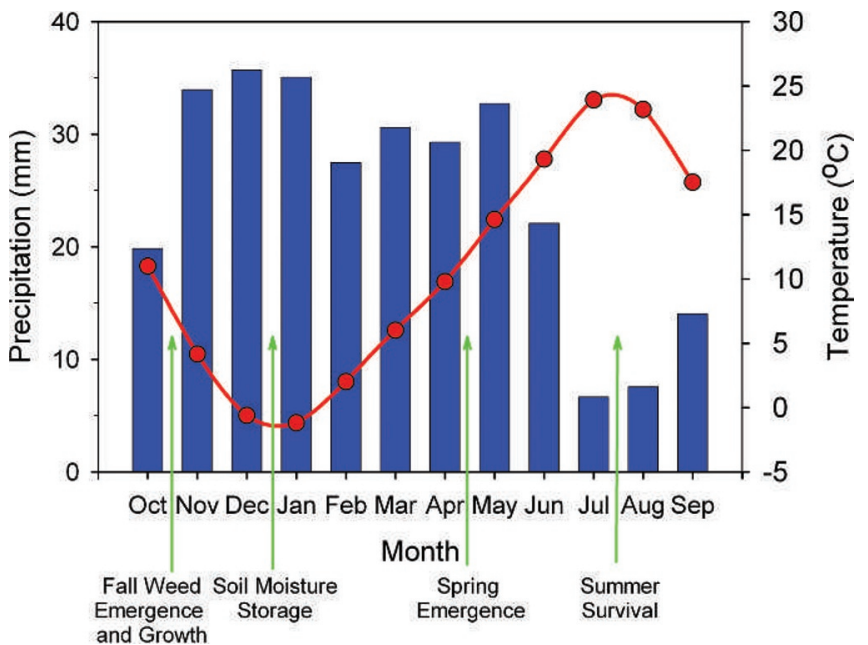

Figure 1. Seasonality of average monthly precipitation (blue) and temperature (red) in Boise, Idaho. Weed competition in the spring can be dependent on fall conditions for early germination and emergence. Growth in the winter is temperature limited, but summer survival can depend on soil moisture storage from winter precipitation. Rapid growth potential as temperatures rise in the spring is offset by the onset of drought conditions at this location.

Multiple sources are now also available for interpolated and modeled historical weather data at monthly (PRISM), ${ }^{\mathrm{x}}$ and daily time steps. ${ }^{8,9}$ Spatially gridded weather data from the Daymet ${ }^{\mathrm{xi}}$ program has also been adjusted to account for the complex topography typical of rangelands in the western United States. ${ }^{10}$ These gridded data products are especially useful in areas that do not have local weather data, but can contain errors introduced by the modeling and interpolation procedures. Individual station data might also contain unknown errors; therefore, it is prudent to use weather data from multiple sources for restoration planning and analysis.

Once you obtain the site-relevant weather data, they can be summarized to provide a general description of the seasonality of precipitation and temperature. Figure 1 provides an example of precipitation and temperature seasonality in Boise, Idaho. Assessment of historical weather variability, however, should be at the temporal resolution relevant to critical or limiting microclimatic factors. Hardegree et al. ${ }^{6}$ calculated seasonal changes in seedbed temperature and moisture at seeding depth and ranked relative favorability of seedbed microclimate at month, season, and annual time scales. Much shorter-term negative effects of freezing and drought can be critical for assessing mortality factors, especially during the transition between the germination and emergence phase. ${ }^{7}$ Spring conditions are especially important to establishment because rising temperatures suitable for rapid growth are accompanied by a drop in precipitation. Winter temperatures generally limit germination, emergence, and seedling growth,

x For more information on PRISM, see http://www.prism.oregonstate.edu. ${ }^{x i}$ For more information on Daymet, see http://daymet.ornl.gov. 
but winter precipitation can determine soil water storage for use later in the spring and summer. All of these time periods can be critical to establishment or mortality within a given year (Fig. 1) and should be assessed individually for their annual variability and potential impact on both positive and negative establishment response.

An additional tool for adaptive management planning is to use long-term climate records to rank precipitation for subsequent assessment of potential site variability, and to facilitate retrospective analysis of past management activities. Figure 2 shows the ranking in March-May precipitation relative to total annual and May precipitation for the Boise, Idaho precipitation record. Several things have been previously noted for these data: annual variability in precipitation is higher for shorter time intervals; and annual, seasonal, and monthly precipitation are only weakly correlated. ${ }^{6}$

\section{Plan Development}

Ranking historical weather data can provide useful insight into the potential need for adaptive management in response to weather-induced variability in success, partial success and failure of establishment (Fig. 2). Partial success might require a planning strategy to sustain growth of initial seedlings, alteration of future seed mixtures to increase biodiversity of initial plant communities, or additional control of invasive weeds in subsequent years until desirable species are firmly established. Adaptive management also requires a monitoring plan which will need to accommodate expected variability in weather-induced success rates. If possible, treatments and controls should be replicated across years so that treatment effects can be separated from weather effects. ${ }^{3}$

\section{Stakeholder Involvement and Adjustment of Plan}

Weather-induced uncertainty in establishment success needs to be explicitly acknowledged when working with stakeholder groups. The EBIPM model is very useful in explaining rangeland management and restoration to stakeholders who do not have much previous experience with dynamic natural systems.

Agency protocols and expectations can also constrain future management actions unless variability and adaptive management are explicitly acknowledged during plan development. Environmental Assessments (EAs) and other National Environmental Policy Act (NEPA) documentation need to anticipate multiyear management actions in response to weather impacts. Most rangeland restoration is conducted reactively in response to wildfire under current Emergency Stabilization and Rehabilitation (ESR) protocols. Burned Area Emergency Response (BAER) teams might be required to develop an emergency stabilization plan within a few weeks of the disturbance event. This time frame might be too limiting to incorporate weather information into adaptive-management, post-fire restoration plans. Weather data access, however, should be anticipated

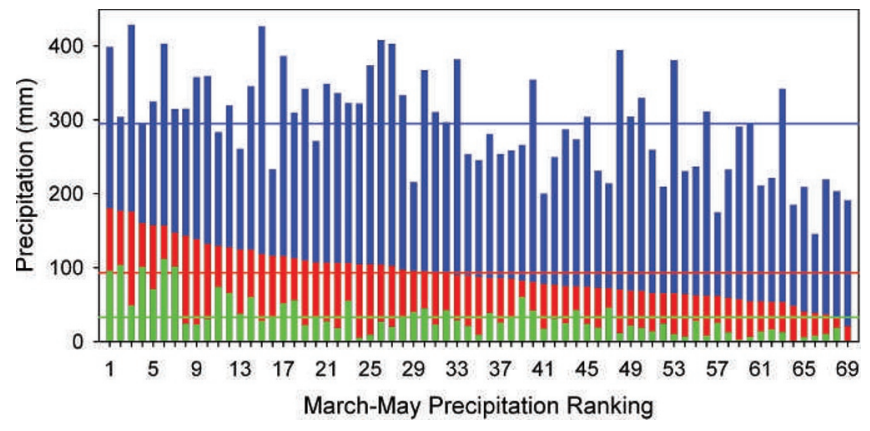

Figure 2. Range of annual (blue), March-May (red), and May (green) precipitation in Boise Idaho, ranked in descending order of March-May precipitation. Annual precipitation is only weakly correlated to growthseason precipitation, so an understanding of establishment success might require more detailed information on specific precipitation patterns during critical periods for establishment.

in advance of ESR needs because the bulk of rangeland restoration funds are linked to emergency appropriations for wildfire response.

\section{Plan Implementation and Data Collection}

We advise that you be weather conscious in plan implementation. Consider collection of on-site weather data, particularly for large restoration projects where the added expense will be relatively small compared to the total restoration budget. Consider expanding vegetation monitoring beyond estimates of biomass and plant density in the year following the seeding activities. ${ }^{3}$ Successful restoration is dependent on multiple processes associated with different stages of plant life history. ${ }^{7}$ Periodic monitoring of emergence and seedling development and on-site daily weather data could yield important information about the specific processes and mechanisms contributing to success or failure in a given project. Longer-term restoration goals require relatively longer-term monitoring to assess success.

\section{Evaluate and Update Plan to Maintain Positive Trajectory}

Success and failure in any given year should always be viewed in the context of the historical weather ranking developed at the beginning of the planning process. Promising seedbed preparation and planting treatments should not be abandoned after failure in poor weather years, and the utility of successful seedbed treatments should not be overestimated in good establishment years. Continue to monitor both controls and treatments over multiple years to capture long-term treatment effects. Figure 3 shows a simplified model of vegetation dynamics in a sagebrush/bunchgrass rangeland in the Intermountain western United States, but this diagram mostly captures alternative plant community transitions in good and bad restoration years. In most years, landscape-scale treatments produce intermediate results in both space and time, and require active monitoring, assessment, and retreatment in order to achieve longer-term goals. 


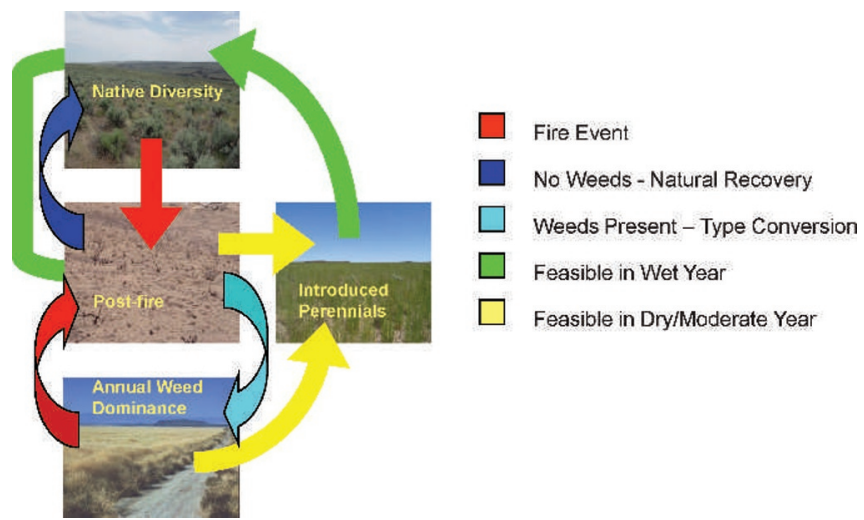

Figure 3. Simplified state-and-transition model for a sagebrush-bunchgrass rangeland in southern Idaho that has been disturbed by wildfire and introduced annual weeds.

\section{Summary and Management Recommendations}

Seasonal weather forecasting technology in the western United States is still a few years off for real-time management applications. The primary utility of historical weather data is in historical analysis of previous restoration and rehabilitation efforts, and in development of weather-centric, long-term adaptive management plans for rangeland restoration. The following are some general principles for use of historical weather data:

- Inherent weather variability in upland rangeland systems requires relatively long-term goal setting and contingency planning for partial success or failure in any given year.

- Proactive adaptive management might have to be implemented at the beginning of a given planning cycle in order to accommodate NEPA requirements for prior approval of potential management activities. Proactive planning for weather variability is possible by anticipating management contingencies for alternative weather impacts on seedbed preparation, seeding, weed control, and other management alternatives.

- Success and failure must be weighed in the context of weather variability, and monitoring programs must be adjusted to accommodate weather-induced limitations to specific inferences about treatment effectiveness across the landscape.

Weather data is increasingly available and should be used whenever possible both in the planning and evaluation stage of EBIPM. Links to previously listed weather data sources, gridded weather datasets, and other planning guidance are available from the EBIPM Web site. .ii $^{\text {This }}$ Web site also contains some simple spreadsheet planning tools that use Daymet and other gridded and point-based meteorological data to automatically generate seasonal weather patterns, and ranking of annual, seasonal, and monthly precipitation with graphical output of the type shown in Figures 1 and 2.

\footnotetext{
${ }^{\text {xii }}$ Access the EBIPM website at http://www.ebipm.org.
}

\section{References}

1. Sheley, R., J. James, B. Smith, And E. Vasquez. 2010. Applying ecologically based invasive-plant management. Rangeland Ecology Eं Management 63:605-613.

2. Hardegree, S. P., J. Cho, And J. M. Schneider. 2012. Weather variability, ecological processes, and optimization of soil microenvironment for rangeland restoration. In: T. A. Monaco and R. L. Sheley [EDs.] Invasive plant ecology and management: linking processes to practice. Wallingford, Oxon, UK: CAB International. p. 107-121.

3. Hardegree, S. P., T. A. Jones, B. A. Roundy, N. L. Shaw, and T. A. Monaco. 2011. Assessment of range planting as a conservation practice. In: D. D. Briske [ED.]. Conservation benefits of rangeland practices: assessment, recommendations, and knowledge gaps. Lawrence KS, USA: Allen Press. p. 171-212.

4. Reever-Morghan, K. J., R. L. Sheley, and T. J. Svejcar. 2006. Successful adaptive management-the integration of research and management. Rangeland Ecology \& Management 59:216-219.

5. Sheley, R., B. Smith, K. Reever-Morghan, and T. SvejCAR. 2009. Adaptive management for invasive annual grasses. A step-by-step user's guide. Burns, OR, USA: USDA-ARS. $32 \mathrm{p}$.

6. Hardegree, S. P., C. A. Moffet, G. N. Flerchinger, J. Cho, B. A. Roundy, T. A. Jones, J. J. James, P. E. Clark, and F. B. Pierson. In press. Hydrothermal assessment of temporal variability in seedbed microclimate. Rangeland Ecology E' Management (in press). doi:10.2111/REM-D-11-00074.1

7. James, J. J., T. J. Svejcar, and M. J. Rinella. 2011. Demographic processes limiting seedling recruitment in arid grassland restoration. Journal of Applied Ecology 48:961-969.

8. Di Luzio, M., G. L. Johnson, C. Daly, J. K. Eischeid, and J. G. Arnold. 2008. Constructing retrospective gridded daily precipitation and temperature datasets for the conterminous United States. Journal of Applied Meteorology and Climatology 47:475-497.

9. Авatzoglou, J. T. 2011. Development of gridded surface meteorological data for ecological applications and modelling. International Journal of Climatology. 11 p. doi:10.1002/ joc. 3413

10. Thornton, P. E., And S. W. Running. 1997. Generating surfaces of daily meteorological variables over large regions of complex terrain. Journal of Hydrology 190:214-251.

Authors are Plant Physiologist, USDA-ARS Northwest Watershed Research Center, 800 Park Blvd., Suite 105, Boise, ID 83712, USA, stuart.hardegree@ars.usda.gov (Hardegree); Research Meteorologist, USDA-ARS Great Plains Agroclimate and Natural Resources Research Unit, 7207 W. Cheyenne St., El Reno, OK, 73036, USA (Schneider); and Assistant Professor, The Samuel Roberts Noble Foundation, 2510 Sam Noble Parkway, Ardmore, OK 73401, USA (Moffet). USDA is an equal opportunity provider and employer. 